\title{
Hyperglycemia in Streptozotocin-Induced Diabetes Leads to Persistent Inflammation and Tissue Damage Following Uveitis Due to Reduced Levels of Ciliary Body Heme Oxygenase-1
}

\author{
Settimio Rossi, Michele D'Amico, Annalisa Capuano, Mary Romano, \\ Pasquale Petronella, and Clara Di Filippo \\ Department of Experimental Medicine, Second University of Naples, 80138 Naples, Italy
}

Received 23 February 2006; Revised 7 April 2006; Accepted 10 April 2006

This study investigated the heme oxygenase-1 (HO-1) and the endotoxin-induced uveitis (EIU) in diabetic streptozotocin (STZ)hyperglycemic rats. STZ-hyperglycemic rats had impaired levels of the enzyme HO-1 within the ciliary bodies if compared with the nondiabetic rats. STZ-hyperglycemic rats also predisposed the eye to produce high levels of both the cytokines IL- $1 \beta$ and CXCL8. Subsequent EIU further and significantly $(P<.01)$ increased the cytokines production, an effect partly prevented by hemin treatment. Most importantly, hemin, an inducer of heme oxygenase expression and activity, recovered the huge number of infiltrated polymorphonuclear leukocytes PMN within the ciliary bodies associated with STZ-hyperglycemic state and EIU damage. Impairment of the stress-sensitive enzyme HO-1 in STZ-hyperglycemic rats increases and prolongs the inflammatory response to EIU.

Copyright (c) 2006 Settimio Rossi et al. This is an open access article distributed under the Creative Commons Attribution License, which permits unrestricted use, distribution, and reproduction in any medium, provided the original work is properly cited.

\section{INTRODUCTION}

Endotoxin-induced uveitis (EIU) is an animal model of acute ocular inflammation. Cytokines, chemokines, and nitric oxide (NO) have been reported to play important roles in promoting the inflammation and cell injury of the ciliary bodies in this pathology. Usually, this experimental pathology lasts up to 72 hours and has similarities with the human pathology [1].

Interestingly enough, the cell damage induced by the EIU is strongly reduced by the heme oxygenase ( $\mathrm{HO})-1$ [2]. HO-1 in injured tissues represents an adaptive and defensive response to the inflammatory process [3], and during EIU it has protective effects against the ocular inflammation induced by lipopolysaccharide (LPS) by downregulating proinflammatory cytokines expression in normoglycemic rats [2].

Several studies have demonstrated that diabetes is a risk factor for developing ocular diseases, increasing their prevalence and severity. Progression to severe eye pathologies with loss of supporting structures is mediated by several factors, including oxidative stress, free radicals, secretion of a broad spectrum of inflammatory, and destructive mediators such as cytokines (TNF-alpha, IL-1b, and IL-6), chemokines (IL8), and prostaglandin E2. This is caused by indirect effects of hyperglycemia [4].

The present study focuses on the likelihood that hyperglycemia in diabetes worsens the inflammatory response of EIU by interfering with the HO- 1 expression and activity. We used LPS for the induction of EIU and streptozotocin to induce diabetes, insulin $1.5 \pm 0.5 \mathrm{U} /$ day for 8 days to yield hyperglycemia (blood glucose levels of approximately $22 \mathrm{mmol} / \mathrm{L} ; 396 \mathrm{mg} / \mathrm{dl}$ ) (poor glycemic controlled rats).

\section{MATERIALS AND METHODS}

All experimental procedures and protocols used in this investigation were reviewed and approved by the Animal Care and Use Committee of the Medical College of Naples. Experiments were conducted in male Sprague-Dawley rats (four to six months old and weighing on average $250 \mathrm{~g}$ ), diabetes was induced according to the described procedures [5]. Particularly, streptozotocin was administered at $70 \mathrm{mg} / \mathrm{kg}$ ip and insulin $(1.5 \pm 0.5 \mathrm{U} /$ day ip) was applied to rats in order to yield blood glucose levels of approximately $22 \mathrm{mmol} / \mathrm{L}$ $(396 \mathrm{mg} / \mathrm{dl})$ for 8 days (poor glycemic controlled rats). 
TABLE 1: Schematic representation of the experimental groups and measures done for each group.

\begin{tabular}{|c|c|c|}
\hline \multicolumn{2}{|c|}{ Experimental groups } & Measures \\
\hline Nondiabetic rats & Diabetic rats (streptozotocin, $70 \mathrm{mg} / \mathrm{kg}$ ip) & \multirow{5}{*}{$\begin{array}{l}\text { In each group the levels of } \\
\text { the following parameters } \\
\text { were measured: HO-1, } \\
\text { MPO, IL-1beta, CXCL8 }\end{array}$} \\
\hline Vehicle (saline, $0.1 \mathrm{~mL}$ ) & Vehicle (saline, $0.1 \mathrm{~mL}$ ) & \\
\hline Vehicle + LPS (200 $\mu \mathrm{g}$ in $0.1 \mathrm{~mL})$ & Vehicle + LPS $(200 \mu \mathrm{g}$ in $0.1 \mathrm{~mL})$ & \\
\hline Hemin ( $50 \mathrm{mg} / \mathrm{Kg}$ ip in $0.1 \mathrm{~mL}, 1 \mathrm{~h}$ prior to LPS) & Hemin $(50 \mathrm{mg} / \mathrm{Kg}$ ip in $0.1 \mathrm{~mL}, 1 \mathrm{~h}$ prior to LPS) & \\
\hline Zn-PP ( $50 \mu \mathrm{g} / \mathrm{Kg}$ ip, $6 \mathrm{~h}$ before hemin $)+\mathrm{LPS}$ & $\mathrm{Zn}-\mathrm{PP}(50 \mu \mathrm{g} / \mathrm{Kg}$ ip in $0.1 \mathrm{~mL}, 6 \mathrm{~h}$ before hemin $)+\mathrm{LPS}$ & \\
\hline
\end{tabular}

\section{Induction of EIU}

Rats were injected in one footpad with $200 \mu \mathrm{g}$ of lipopolysaccharide (LPS, Salmonella minnesota, Sigma, St Louis, Mo, USA) in $0.1 \mathrm{~mL}$ of sterile pyrogen-free saline [6].

\section{Treatment with hemin}

An intraperitoneal injection of $50 \mathrm{mg} \mathrm{kg}^{-1}$ hemin (Fluka, Buchs SG, Switzerland), an inducer of HO-1, was given 1 hour before LPS injection. The dose of hemin $\left(50 \mathrm{mg} \mathrm{kg}^{-1}\right)$ was chosen in accordance with previous studies in rats $[2,7$, 8]. In addition zinc protoporphirin-IX (ZnPP-IX) was used as inhibitor of the HO- 1 at dose of $50 \mu \mathrm{g} / \mathrm{kg}$ ip.

\section{Experimental groups}

Rats were randomly allocated to the groups shown in Table 1. Nondiabetic and diabetic animals were sacrificed at $0,6 \mathrm{~h}$, $12 \mathrm{~h}, 18 \mathrm{~h}, 24 \mathrm{~h}, 48 \mathrm{~h}, 72 \mathrm{~h}$ ( $n=6$ for each time point) when treated with vehicle alone and at the same time points when added of LPS in all other groups.

\section{The iris-ciliary body samples}

The iris-ciliary body (ICB) samples were dissected from the eyes, collected, homogenized, and centrifuged to remove cellular debris. Subsequently the frozen ciliary body tissues were homogenized in a solution containg $0.5 \%$ hexa-decyltrimethyl-ammonium bromide dissolved in $10 \mathrm{mM}$ potassium posphate buffer $(\mathrm{pH} 7)$ and centrifuged for $30 \mathrm{~min}$ at $4,000 \mathrm{xg}$ at $4^{\circ} \mathrm{C}$.

\section{HO-1 quantitation}

This assay was done by using an ELISA kit supplied by Stressgen Biotech Corp (Victoria, BC, Canada). This kit shows sensitivity of $0.78 \mathrm{ng} / \mathrm{mL}$ and ranges up to $25 \mathrm{ng} / \mathrm{mL}$ as furnished by Stressgen. An aliquot $(100 \mu \mathrm{l})$ of tissue supernatant was used.

\section{Myeloperoxidase activity}

The reaction was performed as previously described [9]. Data are reported as units of Myeloperoxidase (MPO) activity per gram of tissue protein (U/g). A standard curve was constructed with different numbers of rats neutrophils that were elicited into the peritoneal cavity at $4 \mathrm{~h}$ in response to application of $5 \mathrm{~mL}$ thioglycollate. Pellets were subjected to three cycles of freeze-thawing. Samples $(100 \mu \mathrm{l})$ were obtained after a final centrifugation at 13,000 rpm for $30 \mathrm{~min}$ on a benchfuge. The MPO reaction was produced with a PMN number ranging from 0 to $220 \times 10^{3}$, obtaining a linear relationship with the absorbance at $620 \mathrm{~nm}$ following the equation: $\mathrm{A}_{620}=4.488 \times$ no. of $\mathrm{PMN}+33.74$, with a $\mathrm{R}^{2}=0.98083$. Data are reported as equivalent numbers of PMN per mg of tissue.

\section{Cytokine quantitation by ELISA}

Tissue IL- $1 \beta$ levels in tissue homogenates $(50 \mu \mathrm{l})$ were determined using a commercially available ELISA specific for the rats cytokine, purchased from R\&D Systems (Abingdon, UK). Briefly, tissue supernatant aliquots $(50 \mu \mathrm{l})$ were assayed for IL- $1 \beta$ and compared to a standard curve constructed with $0-1 \mathrm{ng} / \mathrm{mL}$ of the standard cytokine. The ELISA showed negligible $(<1 \%)$ cross-reactivity with several murine cytokines and chemokines (data as furnished by manufacturer). A similar procedure was followed for determination of the chemokine CXCL8 by ELISA (R\&D Systems, UK) and used according to the manufacturer instructions.

Drugs

STZ, ZnPP-IX were purchased from Sigma-Aldrich (Milan, Italy); this latter compound was dissolved in saline (vehicle).

\section{Statistical analysis}

All values are expressed as mean \pm SEM of number $(n)$ of rats for the in vivo experiments. Statistical analysis was assessed either by Student's $t$ test (when only two groups were compared) or one-way ANOVA followed by Dunnett's test (more than two experimental groups). A probability $P$ value less than 0.05 was considered significant to reject the null hypothesis.

\section{RESULTS}

\section{STZ-hyperglycemic rats}

Blood glucose averaged $6.2 \pm 0.1 \mathrm{mmol} / \mathrm{l}$ in basal conditions and rose to $23.0 \pm 2 \mathrm{mmol} / \mathrm{L} 15$ hours after STZ administration. In STZ-rats, a repeated intraperitoneal intravenous 


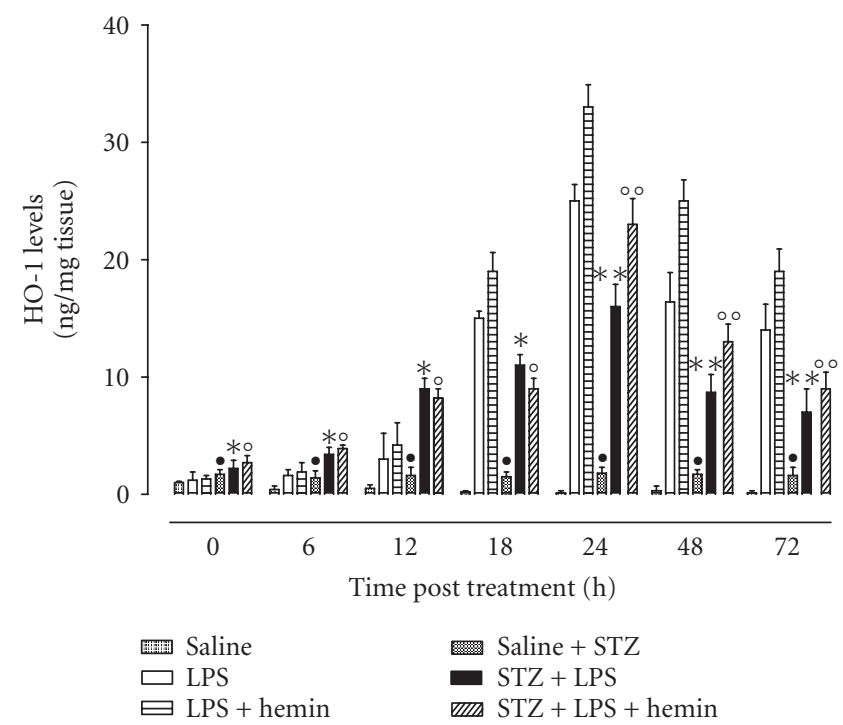

FIgUre 1: STZ-diabetes and HO-1 levels following EIU. Rats were treated ip with vehicle saline; LPS alone (nondiabetic); LPS+STZ (diabetic), or hemin $(50 \mathrm{mg} / \mathrm{kg} 1 \mathrm{~h}$ prior to LPS or LPS+STZ). Significance is expressed as $\bullet P<.05$ versus vehicle saline nondiabetic rats; ${ }^{*} P<.05$ and ${ }^{* *} P<.01$ versus LPS nondiabetic rats; ${ }^{\circ} P<.05$ and ${ }^{\circ} \mathrm{P}<.01$ versus $\mathrm{LPS}+$ hemin nondiabetic rats.

infusion of regular insulin $(1.5 \pm 0.5 \mathrm{U} /$ day $)$ was given and adjusted to yield blood glucose levels of approximately $22 \mathrm{mmol} / \mathrm{L}$ (396 mg/dl) for 8 days. Serum sodium and potassium concentrations and body weight did not significantly change after STZ-treatment (data not shown).

\section{HO-1 quantitation}

In vehicle treated nondiabetic rats ciliary bodies HO-1 level was not appreciable as evidenced by HO-1 ELISA over the time (Figure 1). HO-1 level significantly $(P<.05)$ increased after EIU in nondiabetic rats treated with LPS starting $12 \mathrm{~h}$ post-LPS, reaching a value of $788 \pm 42 \%$ respect to baseline $12 \mathrm{~h}$ later $(P<.001)$. Administration of hemin prior to EIU produced a further and significant increase of HO-1 at all the times (Figure 1). ZnPP-IX+hemin prior to LPS strongly restored the values of HO-1 detected following the LPS alone (data not shown).

HO- 1 was already present in ICB after 8 days of poor glycemic control (Time 0 saline, $+83.3 \pm 11 \%$ versus time 0 nondiabetic; see Figure 1). This HO-1 level remained almost steady even $24 \mathrm{~h}$ later (data not shown). Interestingly, the treatment with LPS increased the levels of HO-1 starting $6 \mathrm{~h}$ after the injection with a peak value at $24 \mathrm{~h}$ time point. This increase was $68 \pm 4 \%$ lower than the incremental expression seen in nondiabetic rats at same $24 \mathrm{~h}$ time $(P<.001)$. LPSinduced HO-1 expression felt within the following 24 and 48 hours (Figure 1). Although hemin treatment, the inducer of HO-1, increased $(P<.01)$ all the figures seen in STZdiabetic rats (Figure 1), the maximum increases in these rats were lower than those observed in LPS-induced nondiabetic

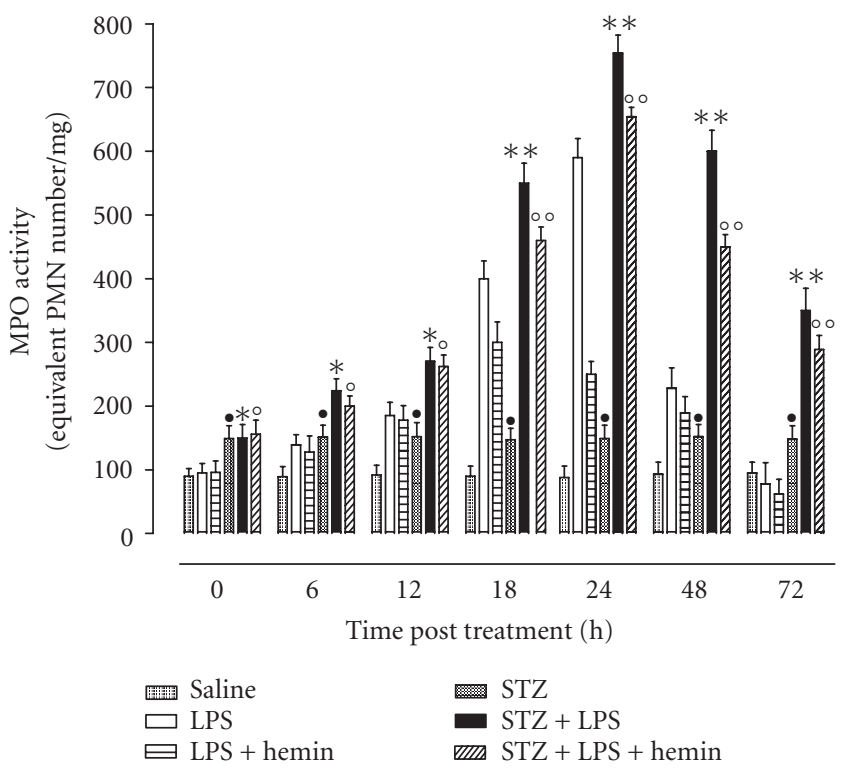

FIgure 2: Myeloperoxidase activity (MPO) in ciliary body. Rats treated as described in Figure 1 had ciliary body collected at the end of the $24 \mathrm{~h}$ endotoxin-induced uveitis and MPO activity determined. Values are mean \pm SEM of $n=6$ rats per group. Significance is expressed as $\bullet P<.05$ versus vehicle saline nondiabetic rats; ${ }^{*} P<.05$ and ${ }^{* *} P<.01$ versus LPS nondiabetic rats; ${ }^{\circ} P<.05$ and ${ }^{\circ} \mathrm{P}<.01$ versus $\mathrm{LPS}+$ hemin nondiabetic rats.

rats subjected to the same treatment and compared at similar time points. This effect on the HO-1 levels started $18 \mathrm{~h}$ after LPS and lasted $72 \mathrm{~h}$ (Figure 1). ZnPP+hemin did not modify the levels observed in the LPS-diabetic condition alone (data not shown). Therefore hyperglycaemia impairs the levels of $\mathrm{HO}-1$ within the ciliary body, a situation patially restored by hemin.

\section{PMN associated EIU damage}

In nondiabetic rats EIU was paralleled by increase in MPO activity in the ciliary bodies versus control rats (ie, saline, time $24 \mathrm{~h}, 93 \pm 14$ equivalent PMN number/mg tissue; LPS time $24 \mathrm{~h}, 640 \pm 30$ equivalent PMN number/mg tissue, $P<$ .001). This LPS-induced MPO value decreased within the following 24 and 48 hours (Figure 2). Administration of hemin produced an attenuation in MPO activity as measured $24 \mathrm{~h}$ post-LPS and at other time points (Figure 2). This attenuation in MPO activity was absent in the rats treated with the hemin $+\mathrm{ZnPP}$ (data not shown).

Control STZ-hyperglycemic rats showed increase in MPO activity with respect to nondiabetic control rats administered with same saline (saline STZ-rats, $152 \pm 28$ equivalent $\mathrm{PMN}$ number/mg tissue; saline nondiabetic, $93 \pm 14$ equivalent PMN number/mg tissue, $P<.05)$. LPS procedure further increased the values of MPO up to $24 \mathrm{~h}$ while decreasing later (Figure 2). The MPO values in STZ-rats were still higher than those in normoglycemic rats (Figure 2) compared at same points. Administration of LPS + hemin produced MPO 
levels still higher than the nondiabetic values measured at any time considered post-LPS (Figure 2). However the association with $\mathrm{ZnPP}-\mathrm{IX}$ reduced the MPO values almost at same values of STZ-EIU rats (data not shown). Hyperglycaemic diabetes produces a worsening of the MPO activity within ICB following uveitis. By potentiating the HO-1 pathway with hemin this MPO activity is almost restored to values of the nondiabetic condition.

\section{Cytokine levels in the ciliary bodies}

At $24 \mathrm{~h}$ time point ciliary bodies IL-1 $\beta$ and CXCL8 levels were slight appreciable in control nondiabetic rats, (saline, $22 \pm 3 \mathrm{pg} / \mathrm{mg}$ tissue and $100 \pm 26 \mathrm{pg} / \mathrm{mg}$ tissue, resp). LPSinduced uveitis showed $24 \mathrm{~h}$ levels of the IL- $1 \beta$ and CXCL8 up to values of $210 \pm 21 \mathrm{pg} / \mathrm{mg}$ tissue and $590 \pm 34 \mathrm{pg} / \mathrm{mg}$, respectively. The important issue is that the tissue levels of these cytokines after $48 \mathrm{~h}$ and $72 \mathrm{~h}$ were decreased (Figure 3 ). Hemin prior to the LPS produced a significant reduction in IL- $1 \beta$ and CXCL8 levels within the tissue (Figure 3 ). This reduction was absent in the rats treated with the hemin $+\mathrm{ZnPP}-$ IX (data not shown).

STZ-hyperglycemia predisposed the eye to produce high levels of both the cytokines IL- $1 \beta$ and CXCL8 as assayed $24 \mathrm{~h}$ after saline injection (ie, $83 \pm 14 \mathrm{pg} / \mathrm{mg}$ tissue and $198 \pm 30 \mathrm{pg} / \mathrm{mg}$ tissue, resp). Subsequent EIU further and significantly $(P<.01)$ increased the cytokines production (Figure 3). Hemin decreased the cytokines production with levels being still higher than those in nondiabetic rats (Figure 3). The association of ZnPP-IX and hemin report the cytokine levels to almost the values assayed in the rats subjected to STZ treatment (data not shown).

Ciliary IL- $1 \beta$ and CXCL8 increase after EIU in nondiabetic LPS-rats and much more following the concomitance of diabetes. The inducer of the HO-1 activity hemin protects the eye from the release of cytokines both in normoglycaemic and hyperglycaemic states. However the effect of this compound in this latter circumstance is lower, in agreement with results shown on the fact that the endogenous HO- 1 is impaired by the diabetes.

\section{DISCUSSION}

This study shows that 8 days of hyperglycemia or poor glycemic control in STZ-diabetic rats lead to more persistent inflammation and tissue damage following EIU. The inflammatory response was evidenced here by higher and more prolonged production of cytokines and chemokines as well as PMN infiltration into the ciliary bodies of STZhyperglycemic rats compared with nondiabetic rats. In spite of several reports in humans and animals addressing (i) the stimulation of an inflammatory response and release of inflammatory mediators by diabetes [10] and (ii) the importance that this response has on the severity of different pathologies [11] the present study is noteworthy the first report showing that this condition also enhances the inflammatory response during the EIU.

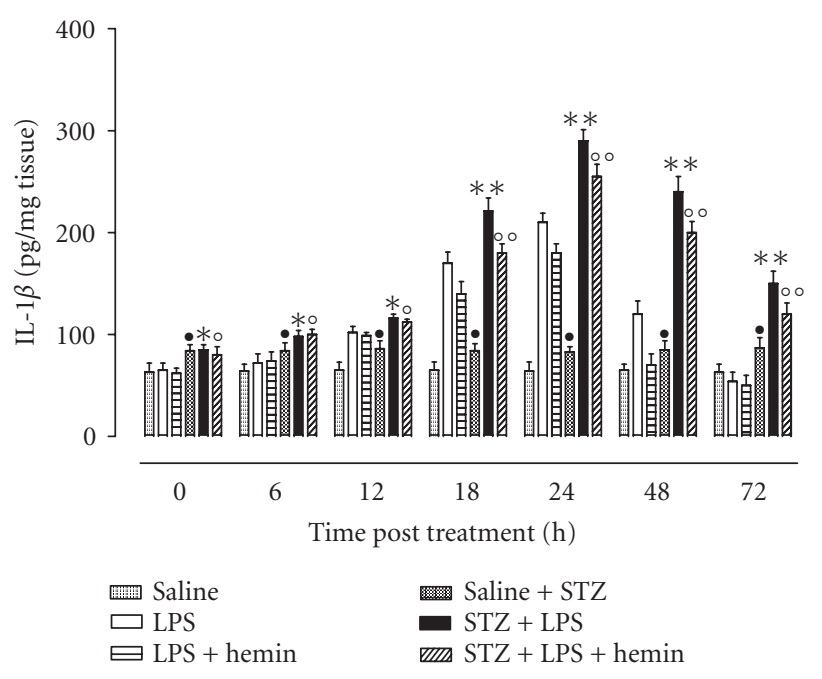

(a)

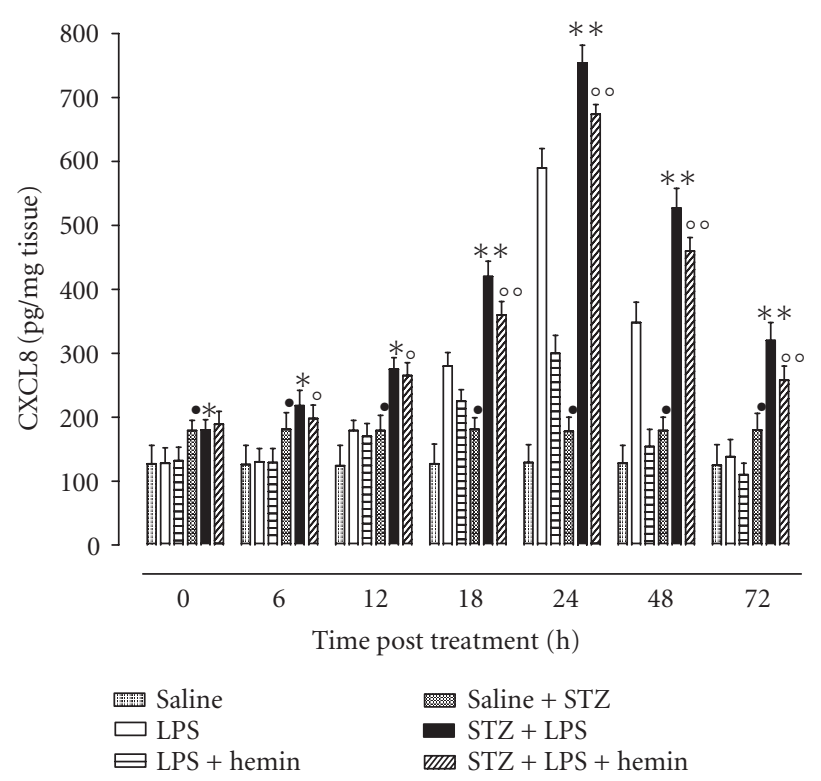

(b)

Figure 3: HO-1 induction reduces cytokine levels in the ciliary body. Tissues at each time point of the EIU procedure were collected from $n=6$ rats for each group and were analysed for IL- $1 \beta$ or CXCL8 determined by ELISA. Significance is expressed as $\bullet P<.05$ versus vehicle saline nondiabetic rats; ${ }^{*} P<.05$ and ${ }^{*} P<.01$ versus. LPS nondiabetic rats; ${ }^{\circ} \mathrm{P}<.05$ and ${ }^{\circ} \mathrm{P}<.01$ versus $\mathrm{LPS}+$ hemin nondiabetic rats.

This study also shows the likelihood that STZ-hyperglycemia causes increased and prolonged inflammation during EIU by impairing the expression of the enzyme HO- 1 within the ciliary tissues. HO-1 in injured tissues represents an adaptive and defensive response to the inflammatory process [3], and during EIU it has protective effects against the ocular inflammation induced by lipopolysaccharide by downregulating proinflammatory cytokines expression in normoglycemic rats [2]. Both LPS-induced ocular response and the expression of the HO-1 enzyme seem to appear earlier in the 
STZ-hyperglycemic rats than in normoglycemic ones. They are already and significantly present in rat ciliary bodies in basal conditions, 6 hours after LPS, increased 18 hours later by reaching the maximum level, and felt within the following 24 and 48 hours. So, diabetes by inducing per se oxidative stress anticipates the insurgence of LPS-induced events, both inflammatory and HO-1 response. Noteworthy, pathophysiological stimuli that increase oxidative stress upregulate $\mathrm{HO}$ $1[12,13]$. In addition to the facts expressed not so far, the evidence that there is difference between the levels of HO-1 found at the peak of the inflammatory response in nondiabetic rats and those in STZ-rats, both subjected to EIU, argues the interesting hypothesis that inflammatory episodes, that increase HO-1 in nondiabetic rats, when superimposed on preexisting hyperglycemia-mediated stress would result in the impairment of the burst of HO-1 expression. This contention based on the fact that the HO-1 levels in STZ-EIUrats may have been impaired by the high production of reactive oxygen species and reduced NO availability occurring in diabetes $[5,14]$. The high peroxinitrite levels formed into the eye may have reduced the $\mathrm{NO}$, thus impairing the $\mathrm{HO}-1$ expression. Actually, NO derived from iNOS enhances $\mathrm{HO}-1$ expression in the tissues [15].

Ciliary bodies of STZ-rats showed higher levels of MPO activity, a marker used to monitor tissue infiltration by PMN [9], even $48 \mathrm{~h}$ and $72 \mathrm{~h}$ after LPS, with respect to nondiabetic normoglycemic rats subjeted to EIU, in contrast to the low levels of the protein HO-1 found in the ELISA assay at the same time points. Interestingly, hemin treatment showed less reduction in MPO levels in STZ-rats as compared with nondiabetic rats at any time point considered. This latter observation supported by previous evidence indicating that induction of HO-1 activity results in reduced expression of adhesion molecules, reduced adhesion and migration of leukocytes following an inflammatory stimulus $[16,17]$.

The causal correlation between HO-1 expression following EIU and white blood cells recruitment into ciliary bodies was confirmed on local generation of leukocyte activators, cytokines, and chemokines which are known to promote leukocyte-endothelium interaction [18]. For this purpose we investigated a cytokine able to increase the adhesive properties of the endothelial wall [19], and that it is implicated in the pathology associated with experimental uveitis [2], the IL-1 beta. As chemokine we chose CXCL8 because it is a chemokine able to recruit neutrophils in rodent species during experimental inflammation [20, 21]. The results of our study showed that the levels of these two cytokines copy the trend observed with the MPO activity. In particular, the reduced HO-1 levels within the ciliary bodies of STZhyperglycemic rats subjected to EIU were mirrored by significant increase in both these cytokines with respect to EIU of nondiabetic rats.

In conclusion, our results demonstrated that streptozotocin-induced hyperglycemic rats had altered HO-1 levels to counteract LPS-induced ocular inflammation in the ICB. Impairment of this stress-sensitive enzyme increases and prolongs the inflammatory response to EIU. It involves a local increase of the expression of cytokines, increased recruitment of PMN and cell damage. Thus in perspective, pharmacological agents that reduce the oxidative stress in hyperglycemic diabetes may reinforce the HO- 1 citoprotection for preventing uveitis as well as in other ocular pathological situations.

\section{ACKNOWLEDGMENT}

This work was supported by the Italian MIUR.

\section{REFERENCES}

[1] Cuello C, Wakefield D, Di Girolamo N. Neutrophil accumulation correlates with type IV collagenase/gelatinase activity in endotoxin induced uveitis. British Journal of Ophthalmology. 2002;86(3):290-295.

[2] Ohta K, Kikuchi T, Arai S, Yoshida N, Sato A, Yoshimura N. Protective role of heme oxygenase-1 against endotoxin-induced uveitis in rats. Experimental Eye Research. 2003;77(6):665-673.

[3] Otterbein LE, Choi AMK. Heme oxygenase: colors of defense against cellular stress. American Journal of Physiology - Lung Cellular and Molecular Physiology. 2000;279(6):L1029-L1037.

[4] Soop M, Duxbury H, Agwunobi AO, et al. Euglycemic hyperinsulinemia augments the cytokine and endocrine responses to endotoxin in humans. American Journal of Physiology - Endocrinology and Metabolism. 2002;282(6):E1276-E1285.

[5] Marfella R, Di Filippo C, Esposito K, et al. Absence of inducible nitric oxide synthase reduces myocardial damage during ischemia reperfusion in streptozotocin-induced hyperglycemic mice. Diabetes. 2004;53(2):454-462.

[6] Yoshida M, Yoshimura N, Hangai M, Tanihara H, Honda Y. Interleukin- $1 \alpha$, interleukin- $1 \beta$, and tumor necrosis factor gene expression in endotoxin-induced uveitis. Investigative Ophthalmology and Visual Science. 1994;35(3):1107-1113.

[7] Hangaishi M, Ishizaka N, Aizawa $T$, et al. Induction of heme oxygenase-1 can act protectively against cardiac ischemia/reperfusion in vivo. Biochemical and Biophysical Research Communications. 2000;279(2):582-588.

[8] Taillé C, Foresti R, Lanone S, et al. Protective role of heme oxygenases against endotoxin-induced diaphragmatic dysfunction in rats. American Journal of Respiratory and Critical Care Medicine. 2001;163(3 I):753-761.

[9] Mullane KM, Kraemer R, Smith B. Myeloperoxidase activity as a quantitative assessment of neutrophil infiltration into ischemic myocardium. Journal of Pharmacological Methods. 1985;14(3):157-167.

[10] Naguib G, Al-Mashat H, Desta T, Graves DT. Diabetes prolongs the inflammatory response to a bacterial stimulus through cytokine dysregulation. Journal of Investigative Dermatology. 2004;123(1):87-92.

[11] Vlassara H, Palace MR. Diabetes and advanced glycation endproducts. Journal of Internal Medicine. 2002;251(2):87-101.

[12] Liu X, Wei J, Peng DH, Layne MD, Yet S-F. Absence of heme oxygenase-1 exacerbates myocardial ischemia/reperfusion injury in diabetic mice. Diabetes. 2005;54(3):778-784.

[13] Di Filippo C, Marfella R, Cuzzocrea S, et al. Hyperglycemia in streptozotocin-induced diabetic rat increases infarct size associated with low levels of myocardial HO-1 during ischemia/reperfusion. Diabetes. 2005;54(3):803-810.

[14] Ceriello A, Quagliaro L, D’Amico M, et al. Acute hyperglycemia induces nitrotyrosine formation and apoptosis in perfused heart from rat. Diabetes. 2002;51(4):1076-1082. 
[15] Datta PK, Gross EJ, Lianos EA. Interactions between inducible nitric oxide synthase and heme oxygenase-1 in glomerulonephritis. Kidney International. 2002;61(3):847-850.

[16] Hayashi S, Takamiya R, Yamaguchi T, et al. Induction of heme oxygenase-1 suppresses venular leukocyte adhesion elicited by oxidative stress: role of bilirubin generated by the enzyme. Circulation Research. 1999;85(8):663-671.

[17] Ajuebor MN, Swain MG, Perretti M. Chemokines as novel therapeutic targets in inflammatory diseases. Biochemical Pharmacology. 2002;63(7):1191-1196.

[18] Vicente AM, Guillén MI, Alcaraz MJ. Participation of heme oxygenase-1 in a model of acute inflammation. Experimental Biology and Medicine. 2003;228(5):514-516.

[19] Ajuebor MN, Virág L, Flower RJ, Perretti M, Szabó C. Role of inducible nitric oxide synthase in the regulation of neutrophil migration in zymosan-induced inflammation. Immunology. 1998;95(4):625-630.

[20] Thorne SA, Abbot SE, Stevens CR, Winyard PG, Mills PG, Blake DR. Modified low density lipoprotein and cytokines mediate monocyte adhesion to smooth muscle cells. Atherosclerosis. 1996;127(2):167-176.

[21] Tailor A, Tomlinson A, Salas A, et al. Dexamethasone inhibition of leucocyte adhesion to rat mesenteric postcapillary venules: role of intercellular adhesion molecule 1 and KC. Gut. 1999;45(5):705-712. 


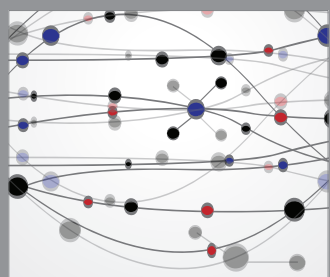

The Scientific World Journal
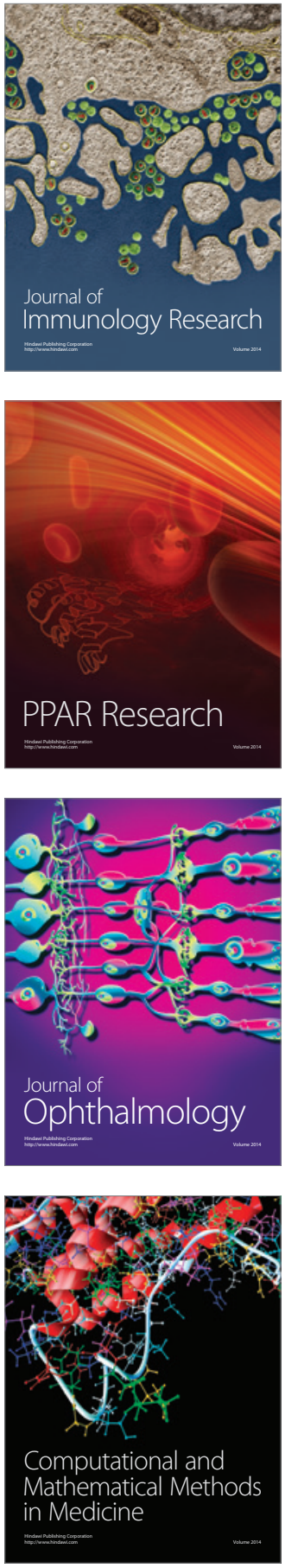

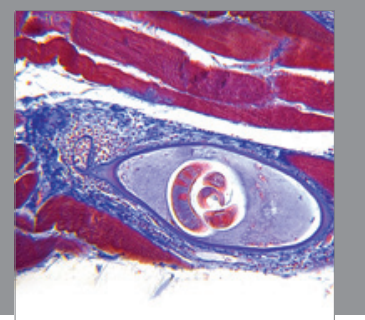

Gastroenterology

Research and Practice
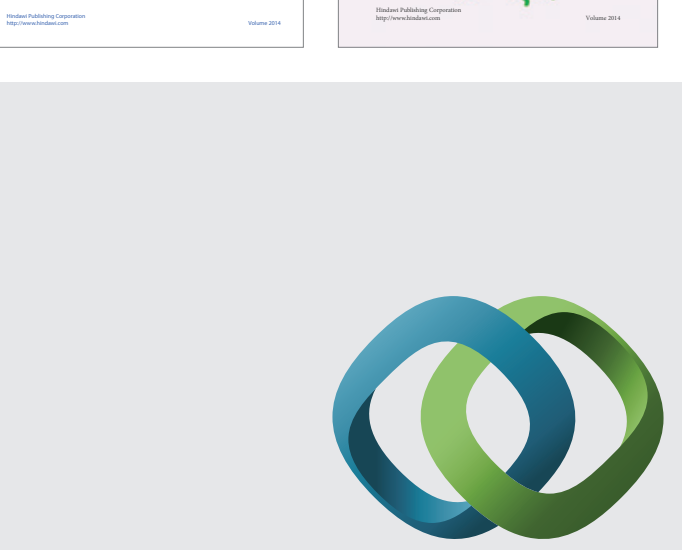

\section{Hindawi}

Submit your manuscripts at

http://www.hindawi.com
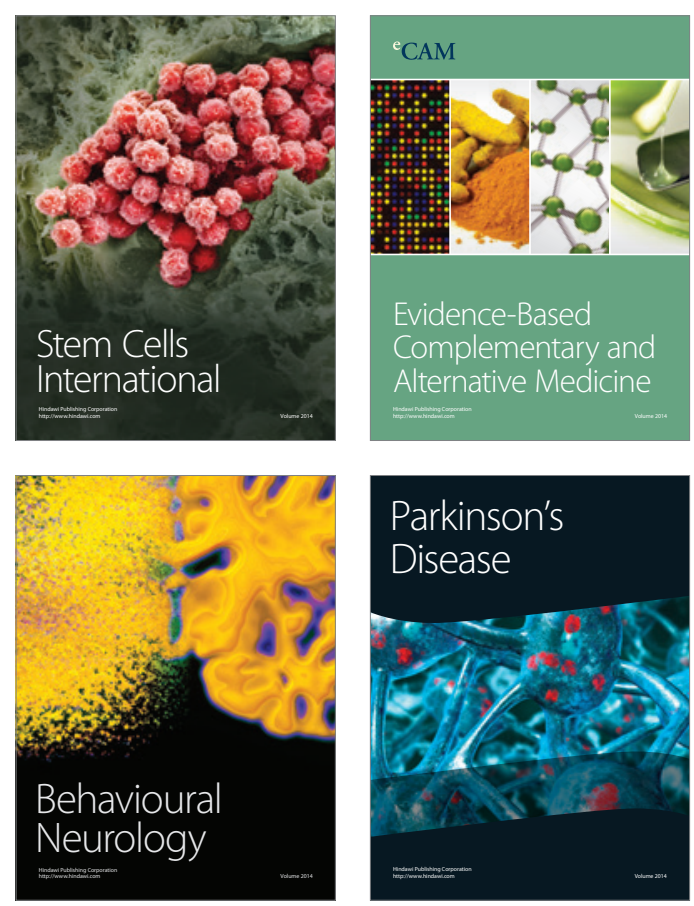

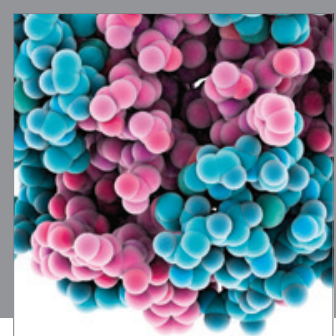

Journal of
Diabetes Research

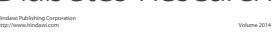

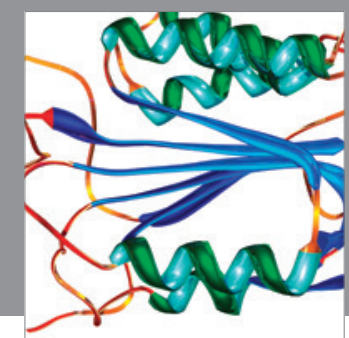

Disease Markers
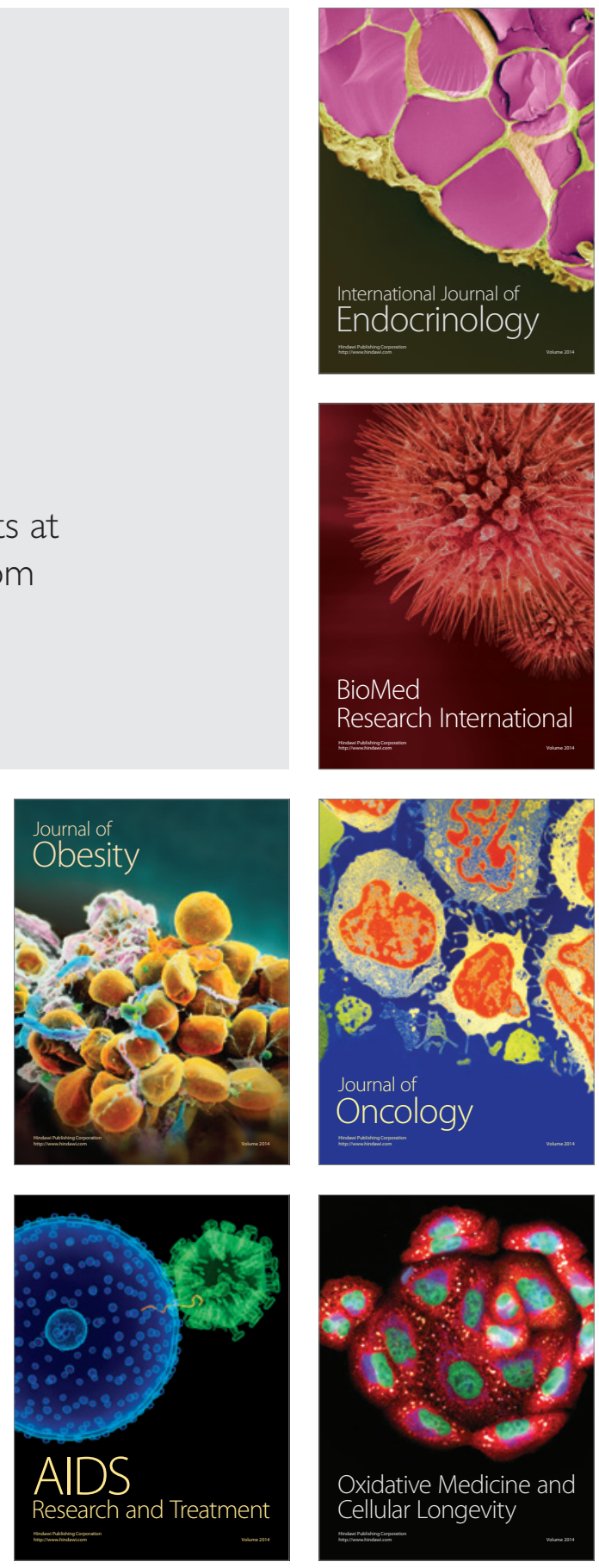